\title{
Case Report \\ First Case Report of Turcot Syndrome Type 1 in Colombia
}

\author{
Vallejo Dora, ${ }^{1}$ Garnica Diego, ${ }^{1}$ Bonilla Rómulo, ${ }^{2}$ and Olaya Natalia ${ }^{3}$ \\ ${ }^{1}$ Human Genetics Research Group, Industrial University of Santander (UIS), Bucaramanga, Colombia \\ ${ }^{2}$ Hospital Universitario de Santander (HUS), Universidad Industrial de Santander (UIS), Bucaramanga, Colombia \\ ${ }^{3}$ Grupo de Patología Oncológica, Instituto Nacional de Cancerología, ESE, Bogotá, Colombia
}

Correspondence should be addressed to Olaya Natalia, nolaya@cancer.gov.co

Received 3 November 2012; Accepted 26 November 2012

Academic Editors: G. Di Vagno, C. Gennatas, A. Goodman, B. I. Razzouk, C. V. Reyes, and G. Tallini

Copyright (๑) 2012 Vallejo Dora et al. This is an open access article distributed under the Creative Commons Attribution License, which permits unrestricted use, distribution, and reproduction in any medium, provided the original work is properly cited.

Turcot syndrome is an autosomal recessive disorder clinically characterized by the occurrence of primary tumors of the central nervous system and adenomatous colonic polyps during the first or second decades of life, with a spectrum of clinical features such as "café-au-lait" spots, axillary freckling, and hyperpigmented spots. Currently its prevalence globally and in Colombia remains unknown. We present the case of a 20 -year-old male with a clinical presentation of both glioblastoma multiforme and multiple adenomatous colonic polyps. The molecular genetics study revealed a mutation in Kras ${ }^{\text {Asp } 12}$ gene and altered expression of HMSH2 and HMSH6 proteins encoded by the DNA mismatch repair genes in two of the colonic polyps. Even though this clinical presentation may suggest a shorter survival rate, this patient is still alive after seven months of treatment. A literature review complements this report.

\section{Introduction}

Turcot syndrome (OMIM: no. 276300, mismatch repair cancer syndrome) is an autosomal recessive disorder [1] characterized by concurrent presentation of a primary tumor of the central nervous system and adenomas or colorectal carcinoma [2], during the first or second decades of life, with a spectrum of clinical features such as "café-au-lait" spots, axillary freckling, and hyperpigmented spots [3]. It is caused by homozygous or heterozygous mutations in the mismatch repair system (MMR) genes: MLH1, MSH2, MSH6, or PMS2, locus on 3p22.2, 2p21, 2p16.3, and 7p 22.1, respectively [4]. Global prevalence is unknown.

\section{Case Report}

A 20-year-old male presented with tonic-clonic seizure and loss of consciousness. He had presented headache and vomiting for the previous 20 days. Both clinical symptoms were compatible with intracranial hypertension. He had history of weakness, weight loss, and other constitutional symptoms, and family history of consanguinity. During the clinical examination, he was fully awake and oriented; a motor deficit in the right side was noticed. On his skin, there were multiple café-au-lait spots and areas of hyperpigmentation (Figures $1(\mathrm{a})$ and 1(b)). Brain CT showed that he had a $4 \times 3 \mathrm{~cm}$ intraparenchymal hemorrhage with mass effect of the left parietotemporal side. He underwent left parietotemporal craniotomy, gross total resection of the tumor, and abscess drainage (Figures 2(a) and 2(b)).

During hospitalization, he was also suffering of lower gastrointestinal tract bleeding. The colon endoscopy revealed 25 colorectal polyps. Histologic analysis of the brain lesion demonstrated a malignant proliferation of pleomorphic and hyperchromatic cells in a background of necrosis. Immunohistochemistry confirmed the glial origin and high proliferation rate. (PFAG positive, high Ki-67 index) (Figures 2(c) and $2(\mathrm{~d})$ ). The tumor was diagnosed as glioblastoma multiforme. Some of the lesions found during colon endoscopy were tubulovillous adenomatous polyps with high-grade dysplasia (Figures 3(a), 3(b), and 3(c)). Adenomatous polyps were negative for HMSH2 and HMSH6 [5] protein expression, which were evaluated by immunohistochemistry (Figure 4). HMLH expression was preserved. Quantitative PCR was performed for evaluating common mutations of the Kras gene. Kras ${ }^{\text {Asp12 }}$ mutation was detected [6]. 


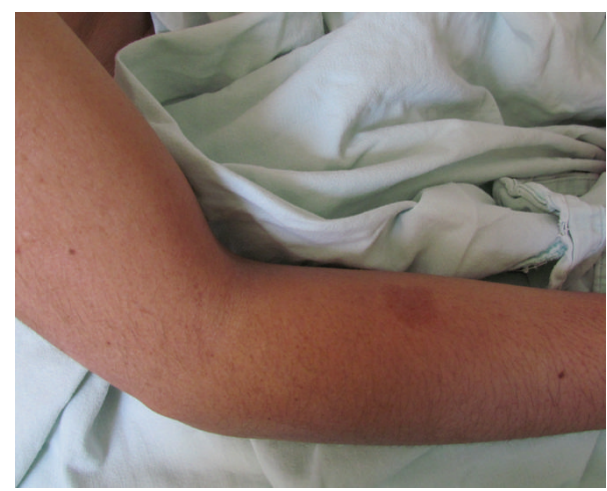

(a)

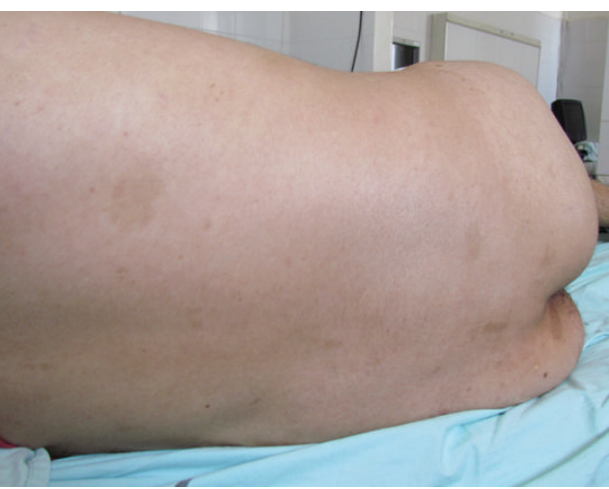

(b)

FIGURE 1: Photograph of the patient skin. It shows multiple café- au- lait macules on the anterior arm side (a) back of $5 \times 3 \mathrm{~cm}$ and buttocks (b).

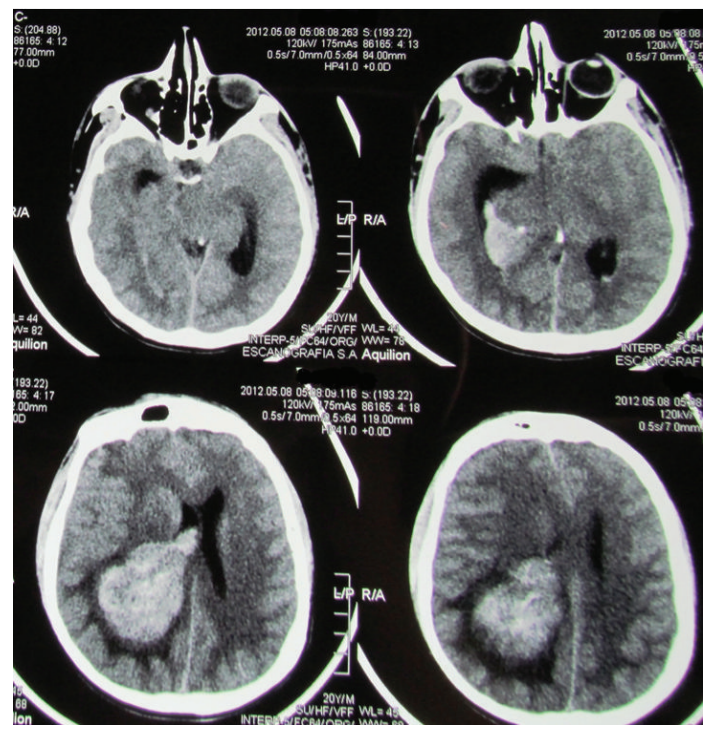

(a)

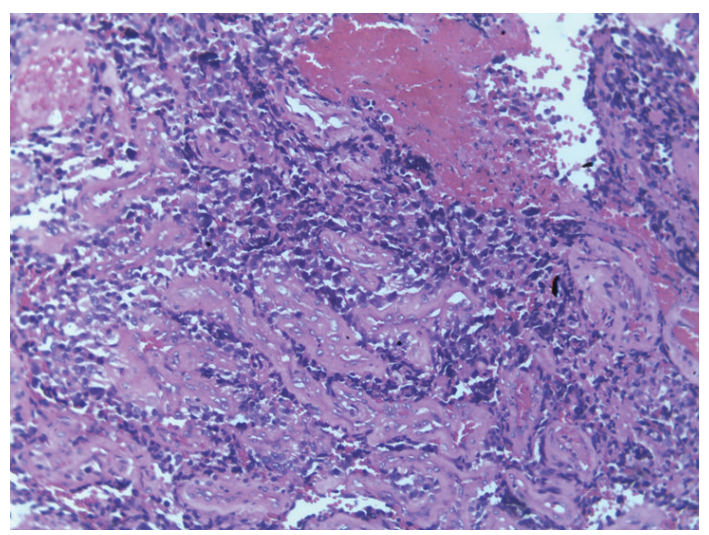

(c)

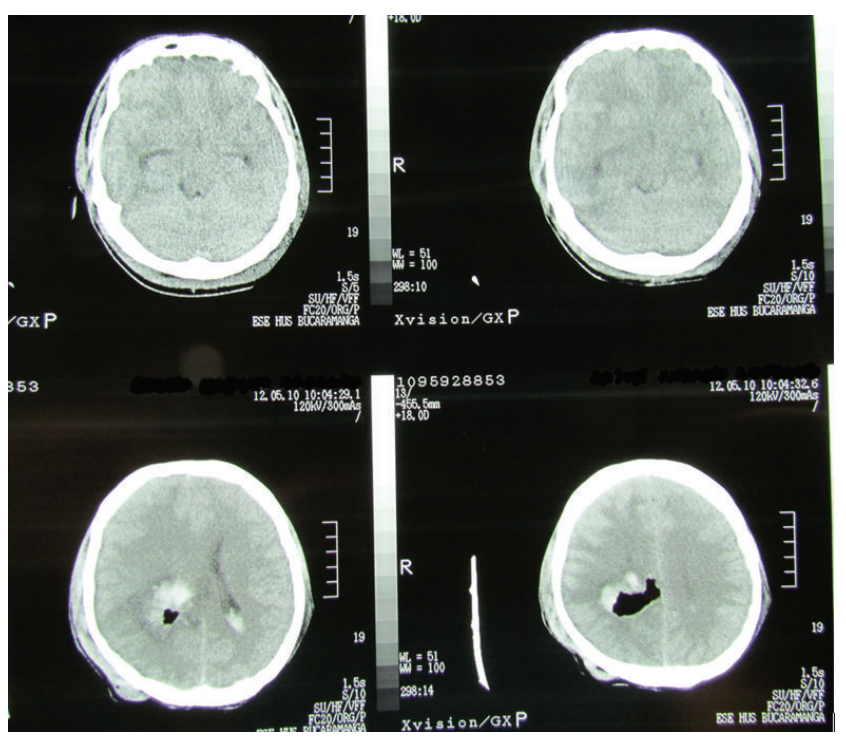

(b)

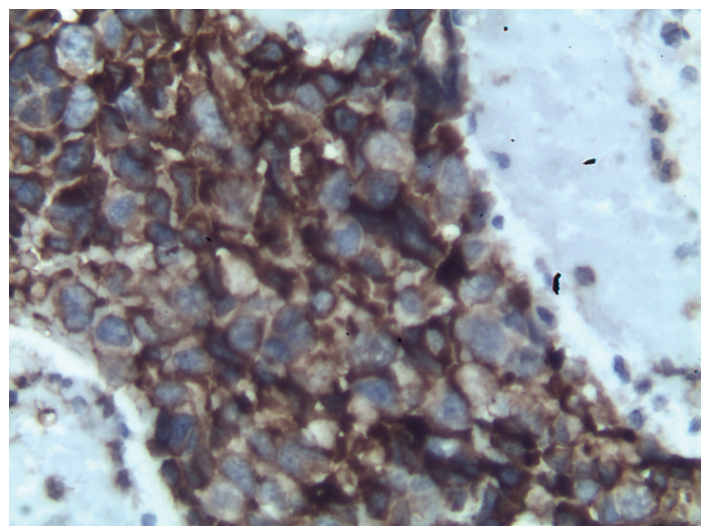

(d)

Figure 2: The brain CT. Parietotemporal tumor and intraparenchymal hemorrhage associated left ventricular drainage system and midline shift (a) and after resection demonstrates no residual tumor and a resolve mass effect (b). Histopathology shows high mitotic index and multinucleated giant cells. Hematoxylin and eosin stain (c). Immunohistochemistry confirmed the glial origin and high proliferation rate and PAFG positive (d). 


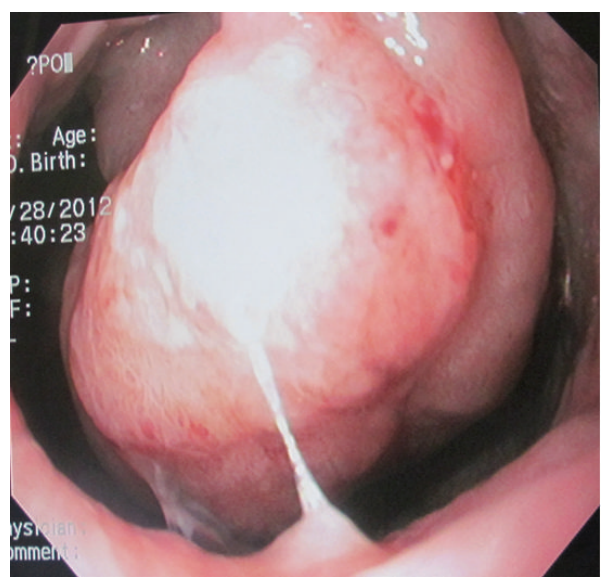

(a)

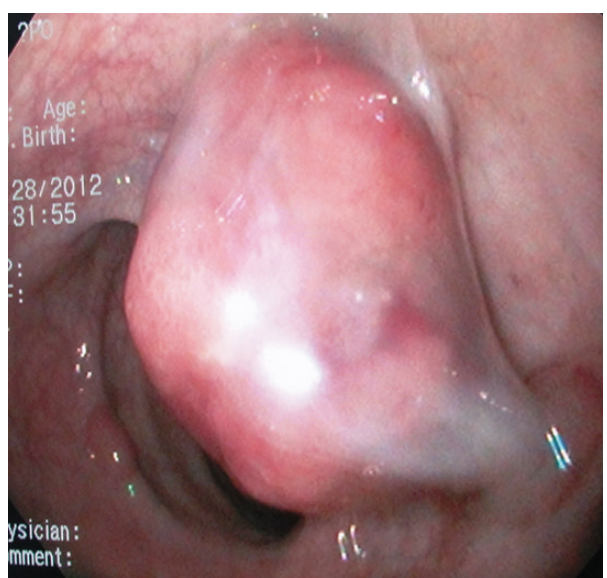

(b)

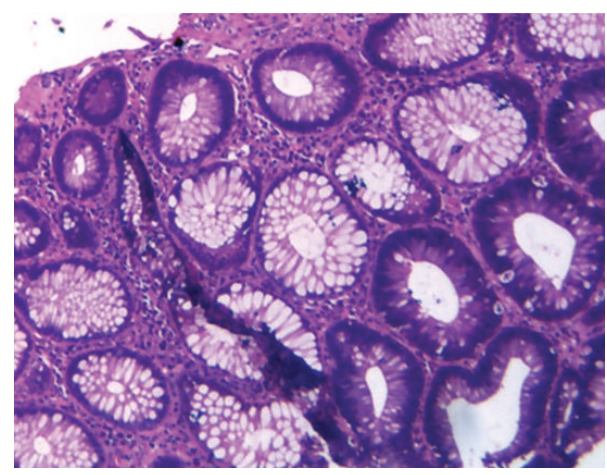

(c)

Figure 3: Colon endoscopy demonstrates tubulovillous adenomatous polyps, a sessile polyp $40 \mathrm{~mm}$ with adenomatous aspect in rectum (a) and in sigmoid colon (b).
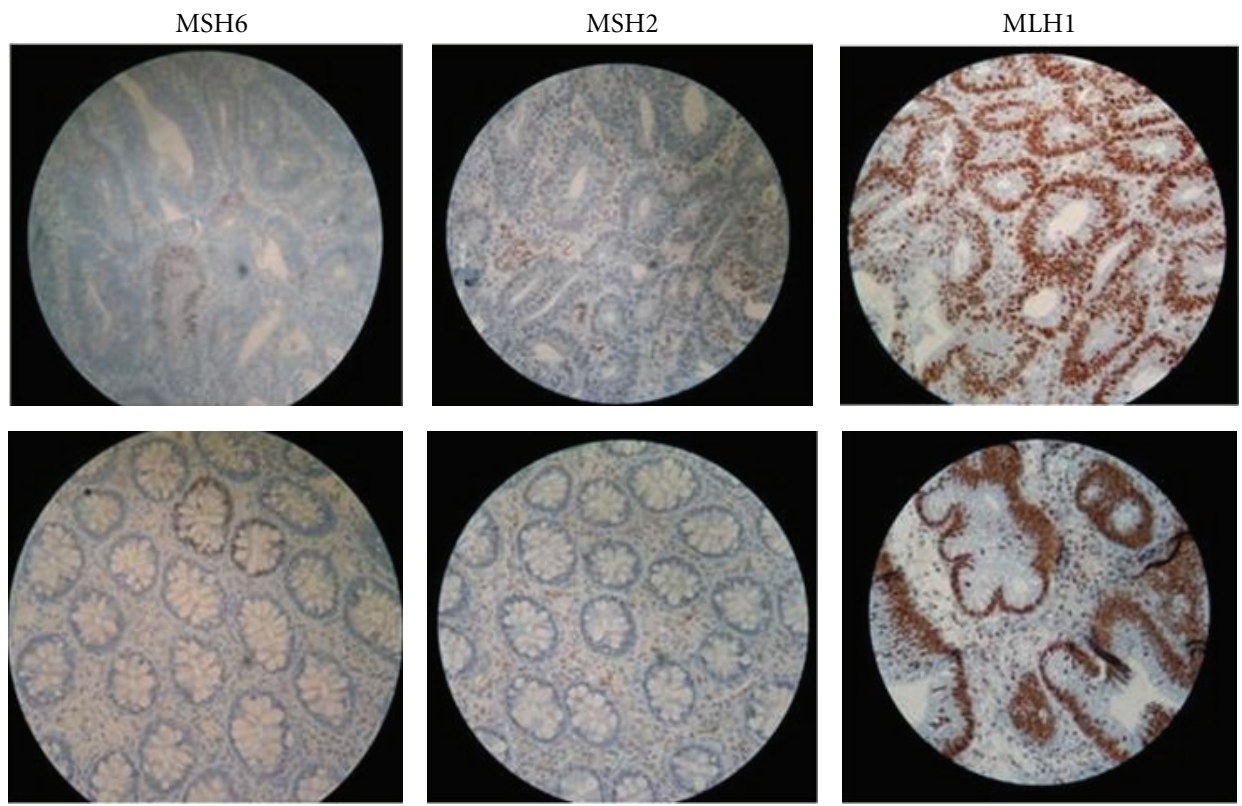

40X ABP

FIGURE 4: IHC evaluation of complex protein expression MMR. Reactivity was observed in the presence of brown coloration in this case there is not involvement of the MLH1 protein, while exhibiting an alteration in the expression of proteins MSH2 and MSH6 as seen in the images of blue coloration polyp 1 . 


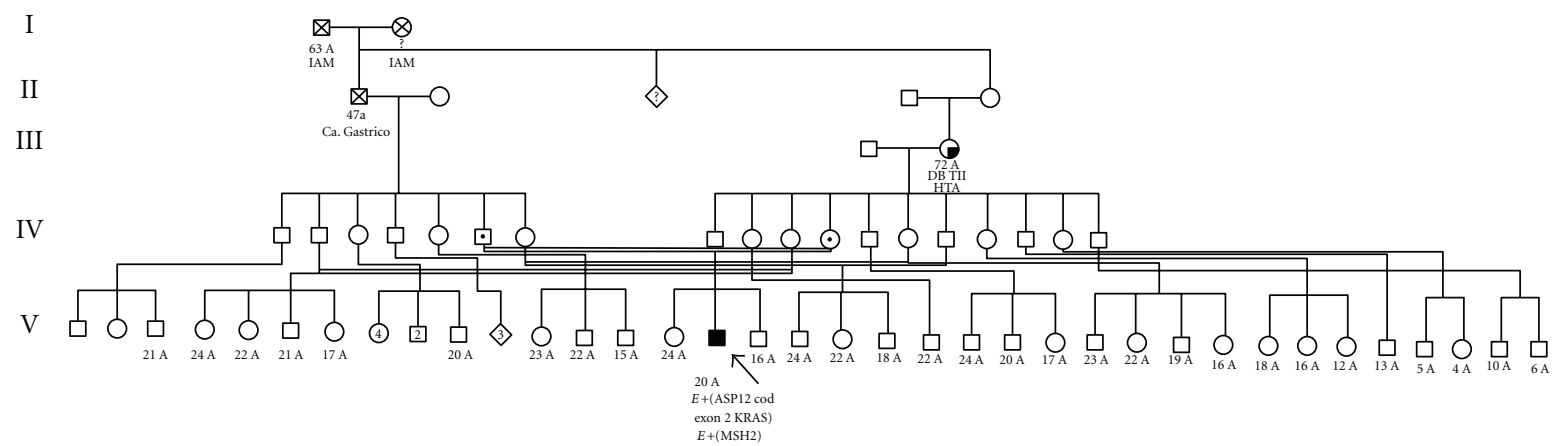

FIgURE 5: Pedigree of the family of the patient illustrates consanguinity in the second generation.

\section{Discussion}

Turcot syndrome is one of the diseases belonging to the hereditary nonpolyposis colorectal cancer syndrome (HNPCC), also known as Lynch syndrome. HNPCC is characterized by an inherited mutation in one of four DNA mismatch repair genes, (MLH1, MSH2, MSH6, and PMS2). These mutations predispose patients to the development of colon cancer and brain tumors, more commonly medulloblastoma. The diagnosis of HNPCC is based on a combination of clinical and genetic criteria. There are two kinds of Turcot syndrome. Patients with Turcot syndrome type 1 , they have been described carrying mutations in the MLH1, MSH2, and the PMS2 genes, but chiefly are found to have mutations in MLH1 and PMS2 MMR gene products are in charge of repair base mismatches and insertion deletion loops during DNA replication. The gene mutations in MMR produce an environment of genetic instability in small repeated gene sequences called microsatellites. When somebody inherits a germline mutation in one allele, a second somatic mutation can occur, allowing for the initiation of tumors. Turcot syndrome type 2, usually found in FAP, presents with innumerable adenomatous polyps [7]. Central nervous system brain tumors occur in both types; type 1 consists of astrocytoma or glioblastoma, and type 2 consists of medulloblastoma [8]. In Latin America, there are four cases of Turcot syndrome reported. Our patient had the phenotypical and pathological findings of Turcot syndrome. As he is the issue of a family with consanguinity (Figure 5), this enabled a precautionary management that improved patient and siblings prognosis. It is imperative to complete the molecular testing and genetic counseling for early diagnosis and preventive management in the family.

\section{Conflict of Interests}

Authors declare no conflict of interests for this Paper.

\section{Acknowledgment}

The authors express their gratitude towards Dra. Clara Inés Vargas.

\section{References}

[1] O. L. Costa, D. M. Silva, and F. A. Colnago, "Turcot syndrome: autosomal dominant or recessive transmission?" Diseases of the Colon and Rectum, vol. 30, no. 5, pp. 391-394, 1987.

[2] F. A. Baughman, C. F. List, J. R. Williams, J. P. Muldoon, J. M. Segarra, and J. S. Volkel, "The glioma-polyposis syndrome," New England Journal of Medicine, vol. 281, no. 24, pp. 1345$1346,1969$.

[3] K. W. Jasperson, W. S. Samowitz, and R. W. Burt, "Constitutional mismatch repair-deficiency syndrome presenting as colonic adenomatous polyposis: clues from the skin," Clinical Genetics, vol. 80, no. 4, pp. 394-397, 2011.

[4] K. Wimmer and J. Etzler, "Constitutional mismatch repair-deficiency syndrome: have we so far seen only the tip of an iceberg?" Human Genetics, vol. 124, no. 2, pp. 105-122, 2008.

[5] D. Ilenčíková, "Constitutional mismatch repair-deficiency syndrome (CMMR-D) — a case report of a family with biallelic MSH6 mutation mutáciou," Klinicka Onkologie, vol. 25, supplement, pp. S34-S38, 2012.

[6] F. Luo, D. G. Brooks, H. Ye et al., "Conditional expression of mutated K-ras accelerates intestinal tumorigenesis in Msh2deficient mice," Oncogene, vol. 26, no. 30, pp. 4415-4427, 2007.

[7] J. Jen, S. M. Powell, T. Berk et al., "The molecular basis of Turcot's syndrome," New England Journal of Medicine, vol. 332, no. 13, pp. 839-847, 1995.

[8] W. K. Cavenee, P. C. Burger, and S. Y. Leung, "Turcot syndrome," in WHO Classification of Tumours of the Central Nervous System, D. N. Louis, H. Ohgaki, and O. D. Wiestler, Eds., pp. 229-231, IARC Press, Lyon, France, 4th edition, 2007. 


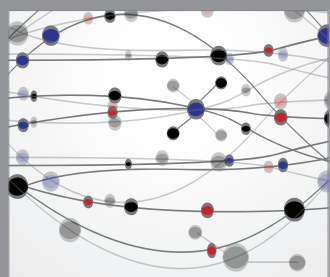

The Scientific World Journal
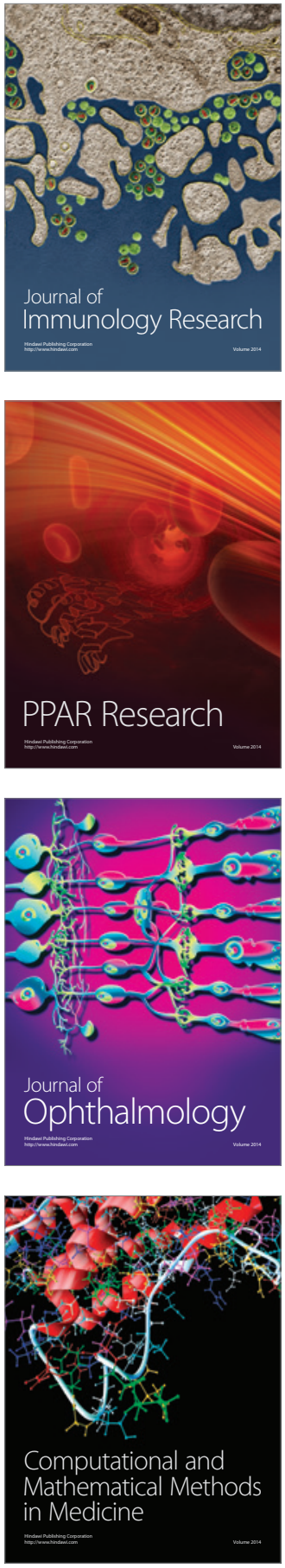

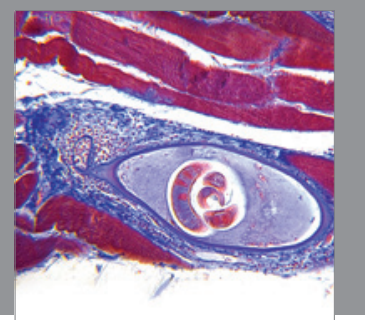

Gastroenterology

Research and Practice
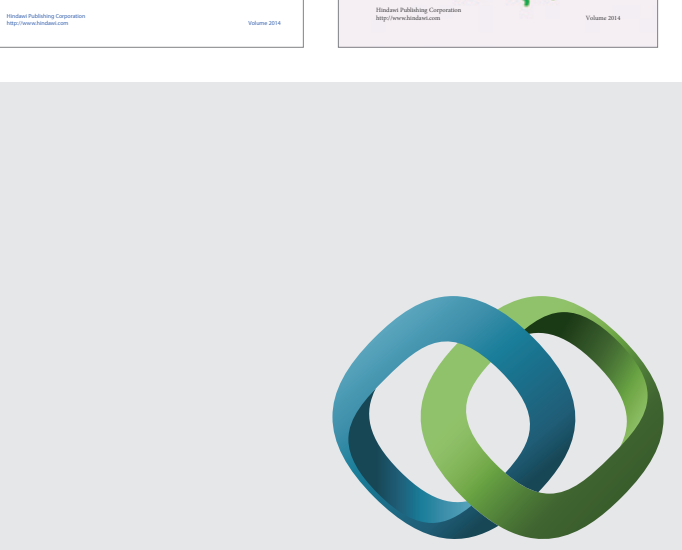

\section{Hindawi}

Submit your manuscripts at

http://www.hindawi.com
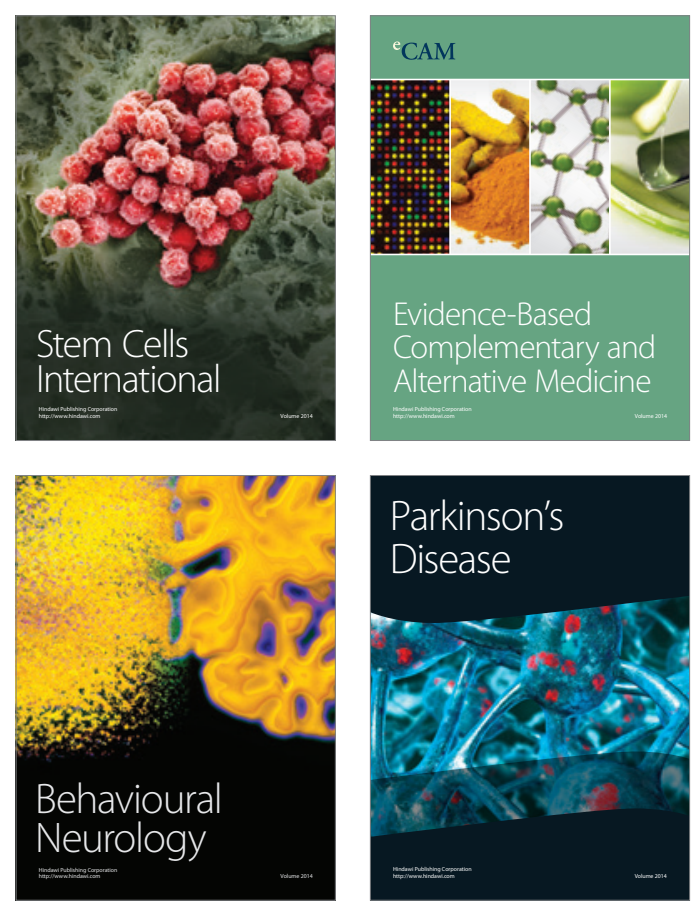

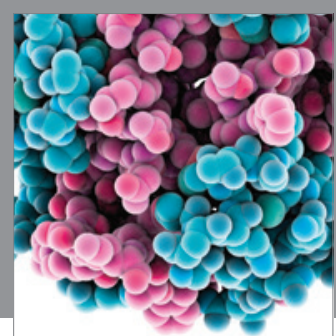

Journal of
Diabetes Research

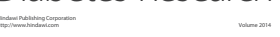

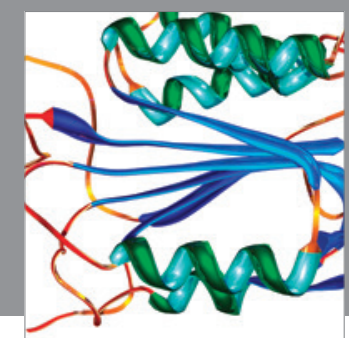

Disease Markers
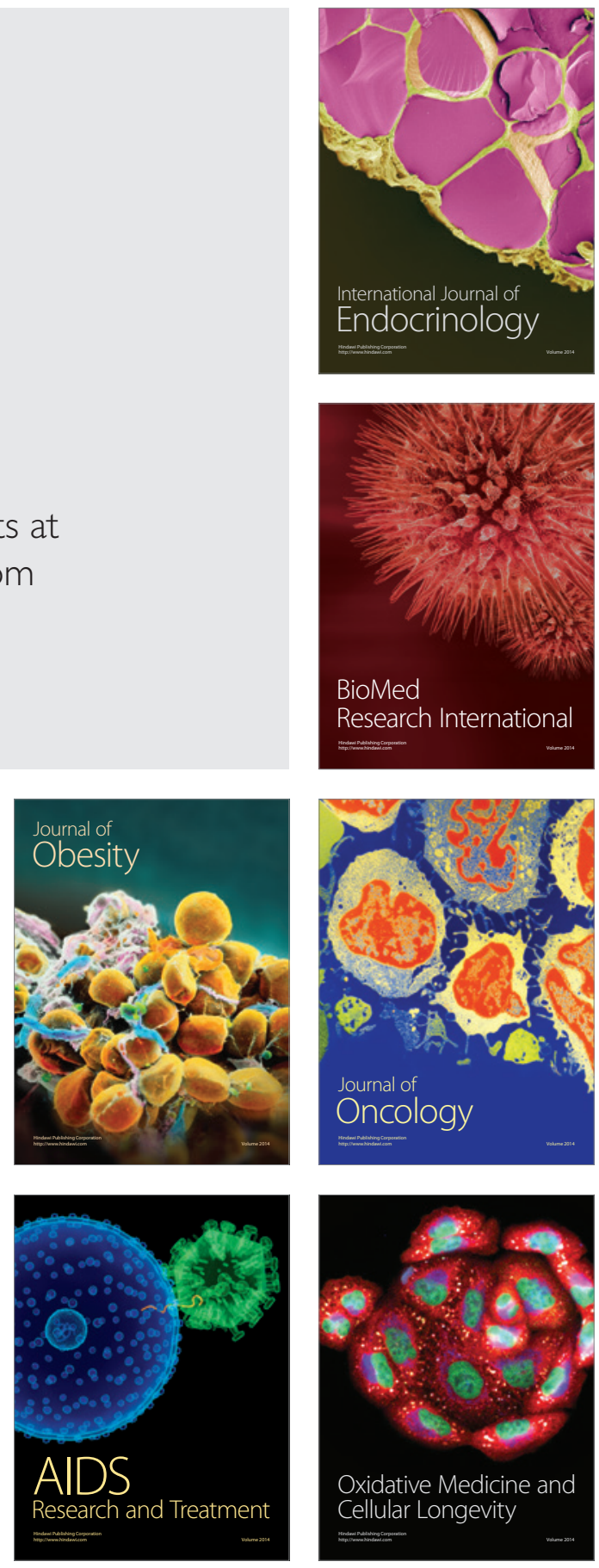